\title{
A DESESTATIZAÇÃO DO SETOR DE TELECOMUNICAÇÕES NO BRASIL
}

THE PRIVATIZATION OF THE TELECOMMUNICATIONS SECTOR IN BRAZIL

Tiago de Jesus Irineu

UFGO - Universidade Federal de Goiás tiagoirineu@outlook.com

Submissão: $13 / 11 / 2014$

Aprovação: 31/12/2015 


\title{
RESUMO
}

Esse artigo tem como objetivo caracterizar o processo de desestatização do setor de telecomunicações brasileiro e delinear a situação vigente nos últimos anos. Para o referido fim, é feita uma revisão sistemática da literatura especializada e uso de dados disponibilizados pela Agência Nacional de Telecomunicações. Ao contrastar a realidade atual das telecomunicações com o período anterior à sua privatização, conclui-se que alguns objetivos das privatizações, como a universalização do acesso e o impedimento de um monopólio privado, foram alcançados. No entanto, problemas regulatórios persistem e demonstram que é necessário padronizar algumas áreas - onde leis municipais e federais se sobrepõem - e instituir uma agência reguladora que esteja atenta a rápidas mudanças tecnológicas e à concentração do mercado de telefonia móvel.

Palavras-chave: Privatizações. Telecomunicações. Telebrás.

\begin{abstract}
This article aims to characterize the privatization process of the Brazilian telecommunications industry and outline the current situation in recent years. For this purpose, it is made a systematic review of the literature and use of data provided by the National Telecommunications Agency. By contrast the current reality of telecommunications with the period prior to its privatization, it is concluded that some goals of privatization, such as universal access and the prevention of a private monopoly, have been achieved. However, regulatory problems persist and show that it is necessary to standardize some areas - where municipal and federal laws overlap - and to establish a regulatory agency that is attentive to rapid technological changes and the concentration of the mobile phone market.
\end{abstract}

Keywords: Privatizations. Telecommunications. Telebrás JEL Classification: L33 


\section{Introdução}

A década de 1990 para a economia brasileira é reconhecidamente uma década de profundas reformas. O país passou por uma troca de moeda e houve o início da abertura comercial do país e também um amplo processo de desestatização da economia, ou seja, a transferência da propriedade total ou parcial de muitas empresas públicas para o controle privado. Tais reformas e mudanças na condução da política monetária culminaram no estabelecimento, a partir de 1999, de um regime macroeconômico baseado em três pilares: austeridade fiscal via geração de superávit primário, metas inflacionárias e câmbio flexível (GIAMBIAGI, PINHEIRO, MOREIRA, 2001).

O processo de privatizações desempenhou um papel fundamental neste esforço reformador e experimentou o seu auge durante a década de 1990. As receitas geradas através das privatizações no ano de 1997 foram maiores do que a soma de todas as receitas anteriores conseguidas por esse processo. Já em 1998, alcançou-se o valor recorde em receita advinda da venda de estatais US\$ 37,5 bilhões. Após isto, as receitas advindas das privatizações caíram paulatinamente de valor, com a venda total ou parcial de estatais praticamente se interrompendo após 2002.

Imagem 1: Receitas geradas pelas privatizações (1991 - 2002)

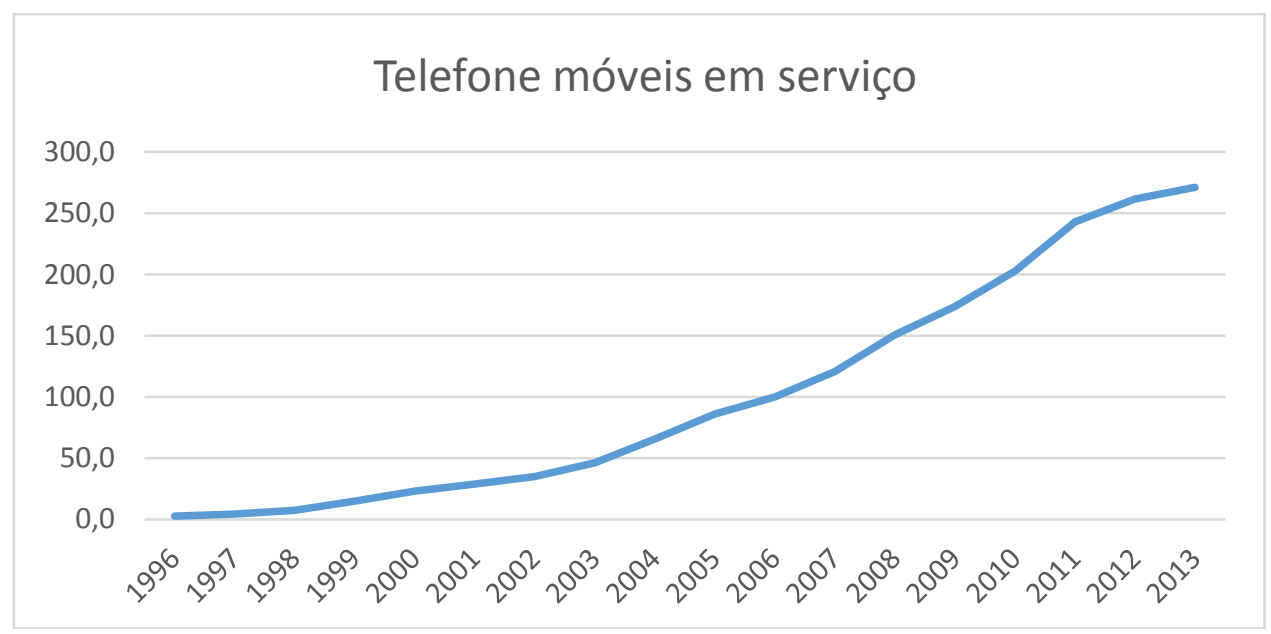

Fonte: BNDES (2002)

O setor que gerou maiores receitas com a sua privatização foi o de telecomunicações, com um valor total de US\$29,811 bilhões e a transferências de dívidas no valor de US\$2,947 bilhões. Para que a desestatização desse setor ocorresse, se fez necessária uma emenda constitucional que acabasse com o monopólio estatal. A criação de uma nova agência reguladora que viesse a regular as empresas concessionárias também se fez necessária. Algo 
que antes não existia já que o único ofertante era uma monopolista estatal. O saneamento do sistema Telebrás, antes dos leilões, também foi preciso para viabilizar os mesmos.

O objetivo do presente artigo é caracterizar como se deu o processo de transferência do controle do setor de telecomunicação das mãos do Estado para a de empresas privadas (1995 - 1998) e qual o papel que foi dado ao Estado no setor após as privatizações. Por fim, é feito uma discussão da situação atual (2014) do setor de telecomunicações e quais lições pode-se retirar das transformações ocorridas no setor a partir das privatizações.

Além desta introdução, o artigo apresenta mais seis seções. Nas seções 3 e 4, são feitas a revisão da literatura e uma breve explicação da metodologia utilizada no presente artigo. $\mathrm{Na}$ seção 5 é feita uma caracterização da situação das telecomunicações no período anterior às privatizações, englobando desde a década de 1960 a meados da década de 1990. Na seção 6, o processo das privatizações compreendido no período de 1995 - 1998 é detalhado. Na seção seguinte é feita uma discussão sobre a situação atual das telecomunicações e na última seção são feitos os comentários finais.

\section{Revisão da literatura}

Os anos 1990 foram marcados por privatizações não apenas no Brasil, mas no mundo como um todo, Megginson e Netter (2001) apresentam uma visão geral da literatura sobre privatizações pelo mundo. Os autores traçam o início desta política no governo Thatcher na Grã-Bretanha (década de 1980), e colocam que tal governo e praticamente todos os demais que buscaram implantar uma agenda de privatizações, declararam como objetivos um aumento das receitas para o Estado, a promoção da eficiência econômica, a redução da interferência do governo na economia, um acesso mais democrático à propriedade dessas empresas e a sujeição das empresas estatais à disciplina do mercado.

Chong e López-de-Silanes (2003) fazem uma análise da literatura empírica com foco no caso latino-americano. Os autores chegam à conclusão que apesar do descontentamento da população desses países, as privatizações apresentaram resultados positivos quando analisado o impacto sob as contas públicas ou sobre o desempenho das empresas privatizadas. E mais do que isto, chegam à conclusão de que os ganhos de lucratividade encontrados nas empresas que foram privatizadas não podem ser explicados em termos de exploração dos trabalhadores ou de poder de mercado.

Velasco Júnior (1999) diferentemente da maior parte da literatura busca não fazer uma análise dos resultados das privatizações, mas explicar quais foram as motivações por trás de 
todo o processo de desestatização da economia, desde o seu início no governo Sarney até o primeiro mandato do governo de Fernando Henrique Cardoso (FHC). Ele chega à conclusão que a principal causa para as privatizações não foi uma mudança ideológica, mas sim questões como um expediente interno do Banco Nacional de Desenvolvimento Econômico e Social (BNDES) durante as primeiras privatizações ainda no governo Sarney ou como uma forma de atenuar o problema do déficit público, como as privatizações ocorridas durante o governo FHC.

Anuatti Neto et al. (2003) apresentam uma análise mais compreensiva do programa brasileiro de privatizações, elaborando uma análise comparativa da performance de cerca de 95\% das empresas que foram privatizadas e analisando a performance posterior às privatizações face os resultados anteriores. Os autores chegam à conclusão de que as empresas privatizadas apresentaram aumento de eficiência. Entretanto, enfatizam que as receitas geradas pelas privatizações serviram para encobrir as deficiências fiscais do país e retardaram os ajustes que eram necessários, como a flexibilização do câmbio. Mas esses problemas não podem ser tratados como culpas das privatizações, mas sim das políticas monetária e fiscal do período imediatamente posterior ao plano real.

Lins (2000) faz uma apresentação do processo de privatização do setor de telecomunicações e coloca que a principal meta desse processo era a transferência de recurso para o estado de maneira não inflacionária, o que na visão do autor foi conseguido. Similar a Chong e López-de-Silanes (2003), ele mostra que a opinião pública após alguns anos começou a demonstrar insatisfação com as privatizações.

Novaes (2000) ressalta que o governo brasileiro conseguiu criar um ambiente competitivo no que se refere às tarifas já no momento da privatização do Sistema Telebrás, mesmo isso significando uma perda no valor esperado das ofertas nos leilões, pois maiores tarifas poderiam significar expectativas de lucros maiores por meio das empresas concorrentes e, portanto uma maior disposição a investir.

Pimenta (1999) apresenta uma visão mais crítica desse processo, defendendo a ideia de que as privatizações das telecomunicações foram resultado da imposição dos "países com capitalismo avançado" que estariam buscando uma liberalização do comércio eletrônico, é interessante notar que essa ideia vai em direção contrária a defendida por Velasco Júnior (1999) e Pinheiro (2000) que enfatizam o papel das privatizações como um instrumento no processo de estabilização da economia brasileira. Já Cavalcante (2011) adota também uma postura crítica em relação às privatizações, mas com foco nos seus efeitos. Segundo ele, dado 
que o foco inicial era a universalização da telefonia fixa, não se pode comemorar que isso tenha sido alcançado atrás da telefonia celular, principalmente com os telefones pré-pagos.

A seguir é feita uma breve discussão sobre a metodologia usada no presente artigo, onde foram buscados os principais dados e porque tais fontes foram utilizadas.

\section{Metodologia}

Para a caracterização da desestatização do setor de telecomunicações será feita uma revisão sistemática da literatura especializada. Este método se mostra válido dado que esse período foi muito bem documentado e estudado devido à importância de tais privatizações. Para informações quantitativas referentes a situação atual do setor de telecomunicações é utilizado dados disponibilizados pela Agência Nacional de Telefonia (ANATEL), como a variação anual do total de linhas de telefonia fixa e móveis e pesquisas de satisfação dos clientes de telefonia.

O BNDES, como a discussão acima deixou clara, teve um papel ativo em todo o processo de privatizações do fim da década de 1980 até o início dos anos 2000. Dado esse papel ativo que o banco teve durante esse processo, parte da literatura utilizada é de pesquisadores na época ligados a ele. O presente artigo também se valeu dos dados referentes aos valores dos leilões realizados. Tanto das privatizações como um todo, como especificamente do setor de telecomunicações.

Foi também realizada uma pesquisa pelos autores do artigo sobre preço cobrado hoje pelas empresas de telefonia para a instalação de linhas de telefonia fixa. Embora não se tenha planos atuais que sejam compatíveis com os vigentes nos períodos anteriores à privatização, será usado o valor cobrado pelo serviço mais básico oferecido. Será utilizado o orçamento oferecido pela empresa de telefonia OI e é possível ter acesso a esses dados ao acessar o site da empresa. Ter ciência desses valores é necessário para fazer uma comparação com os valores cobrados no período anterior à desestatização do setor para a instalação de uma linha telefônica. No próximo capítulo será feita uma sumarização das principais características do setor de telecomunicações no período anterior às privatizações.

\section{A progressiva estatização das telecomunicações}

A situação da telefonia brasileira em meados de 1960 era precária. Havia mais de mil empresas com pouca ou nenhuma conexão entre si (NEVES, 2002). As únicas localidades que realmente contavam com serviços telefônicos eram as áreas atendidas pela CTB (Companhia 
Telephonica Brasileira) o que compreendia $75 \%$ de todas as linhas telefônicas do país e aos estados do Rio de Janeiro, São Paulo, Minas Gerais e Espírito Santo. As tarifas neste período eram definidas nas três esferas do poder público e guardavam pouca relação com os custos das concessionárias. Havia mudanças aleatórias de preços o que desestimulava qualquer tipo de investimento na área. As concessões para exploração do serviço também era feito de maneira descentralizada, as três instâncias do setor público tinham direito a fazer tais concessões, o que resultava na ausência de uma coordenação clara. O setor estava estagnado e para uma população de aproximadamente 70 milhões de habitantes, havia 1 milhão de linhas telefônicas instaladas. É nesse cenário de baixo investimento e demanda crescente que o Estado decide intervir (TATSCH, 2003).

A lei de n 4117 de 1962 cria a Empresa Brasileira de Telecomunicações (Embratel) e o Código Brasileiro de Telecomunicações. O código determinava a criação do Sistema Nacional de Telecomunicações (SNT); colocava sob jurisdição da União a telefonia interestadual e atribuía ao governo federal o papel de explorar os troncos integrantes do SNT. Essa regulamentação autorizava o poder executivo a constituir uma empresa pública para explorar tais troncos, tal empresa viria a ser a Embratel. O Código também criou o Contel (Conselho Nacional de Telecomunicações), que tinha o papel de estabelecer os critérios para a fixação de tarifas em todo o território nacional. Ainda em 1962, o governo federal intervém na CTB e, em 1966, as ações da empresa foram adquiridas de vez pela Embratel.

Em 25 de fevereiro de 1967, foi criado o Ministério das Comunicações, ao qual foi vinculada a Embratel, e a quem foram incumbidas as competências até o momento delegadas ao Contel. Como resultado de todas estas medidas, houve uma melhoria nos serviços interurbanos e internacionais, embora a situação a nível local continuasse ruim.

Com o objetivo de resolver o problema a nível local, foi autorizada a criação de uma sociedade de economia mista através da Lei 5792, de 11 de julho de 1972. Assim nasceu a Telecomunicações Brasileiras S/A - TELEBRAS, vinculada ao Ministério das Comunicações. Após sua criação a Telebrás iniciou o processo de aquisição e absorção das centenas de empresas que prestavam serviços telefônicos no Brasil, também foram instaladas em cada estado uma empresa polo. Nos anos 80, o processo de absorção das empresas telefônicas se consolidou e a Telebrás tornou-se responsável pela operação de mais de 95\% dos terminais telefônicos em serviço no Brasil.

Embora esse novo modelo tenha se mostrado uma evolução à situação precedente, ele a partir do final da década de 1980, começa a dar sinais de esgotamento. A crise fiscal do 
estado brasileiro dificultava maiores investimentos das empresas estatais. A falta de investimentos explica a demanda latente no setor de telefonia e que a Telebrás não conseguia atender. Por exemplo, foi constatado que em 1997 havia uma fila de espera de 13,4 mi de pessoas. (TATSCH, 2003). Esse cenário gerava mercados secundários como o de aluguéis de linhas telefônicas.

Com a falta de recursos para investimentos, a Telebrás recorreu ao sistema de "autofinanciamento". O consumidor financiava a sua própria linha telefônica, pagando um valor que variou de dois mil dólares no início dos anos 90, a mil dólares em 1997, quando tal mecanismo foi finalizado. Após esse pagamento a concessionária tinha 24 meses para a instalação da linha e em troca o consumidor recebia ações da Telebrás (NOVAES, 2000). Esse arranjo dificultava o acesso a tal serviço, dessa maneira os parcos serviços de telecomunicações ficavam restritos aos consumidores com maior renda. A Telebrás também era prejudica pelo valor das tarifas serem reajustados não com base nos seus custos, mas por motivos políticos, principalmente como uma forma de controle de inflação. Além disto, havia a prática de subsídios cruzados, onde as tarifas de empresas e de ligações de longas distâncias eram usadas para subsidiar as tarifas das ligações locais. O que também deprimia a capacidade de investimentos. Foi nesse cenário que o processo de privatizações dos sistemas Telebrás tomou forma.

\section{0 processo de privatizações}

A privatização das telecomunicações estava inserida em um programa maior de desestatização da economia brasileira. Dado o valor conseguido nos leilões do Sistema Telebrás, pode-se dizer que esse foi um dos pontos de destaque de um processo que tinha se iniciado no fim da década de 1980 e tomou folego a partir de meados da década de 90.

Antes da privatização de fato do Sistema Telebrás foi necessário uma série de ajustes, legais ou na organização econômica do Sistema. No aspecto econômico, foi necessário principalmente a correção dos valores tarifários praticados no período. No campo legal foi preciso vencer barreiras como a norma constitucional que estabelecia o monopólio estatal na oferta de serviços de telecomunicação.

Para tornar possível a transformação do monopólio estatal para um sistema de concessões públicas, foi necessária uma série de reformas legais no Brasil. A primeira reforma se dá com a aprovação da Emenda no 8 à Constituição Federal, em oito de agosto de 1995, 
que colocava fim ao monopólio estatal e permitia ao Governo Federal outorgar concessões para a exploração de serviços de telecomunicações.

Em 1996 foi aprovada a Lei ${ }^{\circ}$ 9.295/96 que permitia a licitação de concessões de telefonia celular da banda B. A banda B já surge privatizada e é criada para gerar concorrência às empresas até então estatais que exploravam a banda A de telefonia celular. Em 1997 o Congresso aprovou a Lei Geral das Telecomunicações (Lei $n^{\circ}$ 9.472), que continha as diretrizes para a privatização do Sistema Telebrás e lançava a base regulatória para o setor com a criação da Agência Nacional de Telecomunicações (Anatel).

A Lei Geral teve como principal efeito mudar a função do Estado no setor de telecomunicações. Do papel de provedor que tinha sido estabelecido no Código de 1962 e ratificado na Constituição Federal de 1988, o Estado passa agora a ser o regulador com a missão de garantir a "livre, ampla e justa competição entre as prestadoras" (artigo 6). Com essa mudança se torna necessária a criação de uma agência reguladora que além de definir as regras, exercesse o papel de árbitro nas disputas entre os diferentes agentes econômicos e fiscalizasse a ação das concessionárias (NOVAES, 2002).

A Anatel assim é criada antes mesmo das privatizações. Nesse momento ela tem como principais atribuições à elaboração do Plano Geral de Outorgas, que estabeleceu as regras para as concessões dos serviços de telefonia. E a elaboração do Plano Geral de Universalização do serviço de Telecomunicações (Decreto 2.592 de 15 de maio de 1998), que estabeleceu metas para as empresas concessionárias do serviço de telefonia fixa.

A Anatel teve, portanto um papel preponderante na preparação da privatização da Telebrás. A existência deste marco regulatório bem definido foi importante para o sucesso dos leilões do Sistema Telebrás, pois evitou problemas de risco moral e de incerteza institucional (LINS, 2000).

Como citado anteriormente havia distorções nas tarifas telefônicas praticadas no país. Com o forte processo inflacionário do período, os valores das tarifas foram afetados negativamente por esse processo, gerando uma depreciação contínua no seu valor a partir do final da década de 1970. Em 1975, a assinatura básica era de US\$ 10 e o pulso custava US\$ 0,13. Essa deterioração era resultado da prática de subsídios cruzados, onde as tarifas de ligações internacionais eram usadas para subsidiar a das chamadas locais. Isso acontecia porque o valor das tarifas internacionais não entrava no cômputo da inflação oficial, mas as tarifas locais sim. Portanto para não afetar o índice oficial de inflação o governo permitiria a deterioração do valor das tarifas locais e buscava compensar com o aumento das tarifas 
internacionais (NOVAES, 2002). Observando a tabela 1, é possível notar como as tarifas praticadas no Brasil guardavam pouca relação com o valor das tarifas praticadas internacionalmente e também o subsídio cruzado.

Tabela 1: Tarifas brasileiras em comparação a níveis internacionais - 1995 $^{\mathrm{a}}$

\begin{tabular}{l|ll}
\hline Tarifas & Telebrás & Nível internacional \\
\hline Assinatura residencial (US\$/ mês) & 0.63 & $6-8$ \\
\hline Assinatura comercial (US\$/ mês) & 7.43 & $12-28$ \\
\hline Pulso (3 minutos, US\$/mês) & 0.029 & 0.10 \\
\hline Interurbano (US\$/ 1 minuto) & 0.26 & $0.2-0.5$ \\
\hline Internacional para EUA (US\$/ 1 minuto) & 1.94 & 1.12 \\
\hline
\end{tabular}

${ }^{\mathrm{a}}$ A taxa de câmbio ao final de 1995 era de R\$ 0,97/US\$.

Fonte: Novaes (2000)

Nesse cenário, a Telebrás apresentaria pouca atratividade para o investimento privado. Portanto não restava outra opção ao governo a não ser o reajuste dessas tarifas de maneira de que elas voltassem ao nível internacional e também encerrasse a prática de subsídios cruzados. Dessa maneira, em novembro de 1995, o valor da assinatura residencial foi elevado em cinco vezes e o valor da chamada local em $80 \%$. Em maio de 1997, ou mais um aumento das tarifas locais e uma redução das nas tarifas de longa distância. Dessa maneira é possível notar que ambos os problemas tarifários foram atacados de maneira satisfatória.

Tabela 2: Reajustes tarifários (valores em dólares)

\begin{tabular}{l|l|l|l|l|l|l}
\hline Tarifa & $\begin{array}{l}\text { Valor } \\
\mathbf{1 9 9 4}\end{array}$ & $\begin{array}{l}\text { Reajuste } \\
\mathbf{1 2 / 1 9 9 5}\end{array}$ & $\begin{array}{l}\text { Variação } \\
\mathbf{\%}\end{array}$ & $\begin{array}{l}\text { Reajuste } \\
\mathbf{6 / 1 9 9 7}\end{array}$ & $\begin{array}{l}\text { Variação } \\
\mathbf{1 9 9 5} \mathbf{- 1 9 9 7}\end{array}$ & $\begin{array}{l}\text { Variação } \\
\mathbf{1 9 9 4} \mathbf{1 9 9 7}\end{array}$ \\
\hline $\begin{array}{l}\text { Assinatura } \\
\text { Residencial/mês }\end{array}$ & 0.44 & 2.70 & 513.6 & 10.00 & 270.4 & 2172.7 \\
\hline $\begin{array}{l}\text { Assinatura } \\
\text { Comercial/mês }\end{array}$ & 5.22 & 9.42 & 80.5 & 15.00 & 59.2 & 187.4 \\
\hline $\begin{array}{l}\text { Minuto Local } \\
\text { Minuto }\end{array}$ & 0.022 & 0.036 & 63.7 & 0.058 & 61.1 & 163.3 \\
\begin{tabular}{l} 
Interurbano \\
\hline
\end{tabular} & 0.180 & 0.195 & 8.3 & 0.133 & -31.8 & $-26,1$ \\
\hline
\end{tabular}

Fonte: Novaes (2000)

Havia mais uma complexa questão a ser resolvida pelo governo para a concretização da desestatização do setor de telefonia. Era necessário que se evitasse que um monopólio estatal se tornasse um monopólio privado. Para a concretização desse objetivo o governo escolheu cindir a Telebrás em companhias locais mais a companhia de longa distância. Dessa maneira foram criadas a Tele Norte Leste, a Tele Centro Sul e a TELESP, além da Embratel 
que seria a holding de ligação a longa distância. Também foram criadas oito companhias de telefonia celular que explorariam a banda $\mathrm{A}$, correspondendo às áreas definidas pela Lei Mínima do Serviço Celular, sendo elas, a Telesp Celular, a Telemig Celular, Tele Celular Sul, Tele Centro-Oeste Celular, Tele Norte Celular, Tele Nordeste Celular, Tele Sudeste Celular e Tele Leste Celular.

Em 29 de julho as 12 holdings resultantes da cisão do Sistema Telebrás foram vendidas por um valor total de US\$ 18,944 bi. Representando um ágio sobre a soma do valor mínimo pedido para todas as holdings de $63,3 \%$.

O processo de privatização das telecomunicações no Brasil se deu após um processo de saneamento da empresa estatal, da correção da "mentira tarifária" e da criação de uma agência regulatória que visava definir as regras para as futuras empresas concessionárias. O processo foi complexo, mas dado os valores conseguidos no momento da privatização pode-se considerar que ele foi em geral bem gerido. (NOVAES, 2002)

Tabela 3: Resultados dos leilões das Telecomunicações (em milhões de dólares)

\begin{tabular}{|c|c|}
\hline Empresas/Concessões & Receita de Venda \\
\hline Empresas Federais de Telecomunicações & 19.237 \\
\hline Telefonia Fixa e serviços de longa distância & 11.970 \\
\hline Telefonia Celular - Banda A & 6.974 \\
\hline Oferta aos empregados & 293 \\
\hline Concessões & 9.556 \\
\hline . Telefonia Celular (Banda B + D + E) & 9.428 \\
\hline Empresas Espelho & 128 \\
\hline Empresa estadual & 1.018 \\
\hline Total & 29.811 \\
\hline
\end{tabular}

Fonte: BNDES (2002)

Até aqui foi feito uma caracterização do processo de desestatização do setor de telecomunicações no Brasil. Na próxima será caracterizada a situação atual das telecomunicações brasileiras, para buscar responder se as metas de universalização da telefonia e da criação de concorrência foram alcançadas e qual o panorama atual das telecomunicações brasileiras.

\section{As telecomunicações brasileiras em 2014}

Um dos objetivos das privatizações era a massificação do acesso à telefonia. Segundo os dados disponíveis, pode-se considerar essa meta alcançada. Esse alcance se deu pela penetração do uso de celulares no Brasil. Segundo a Tic Domicílios (2013), 85\% da 
população brasileira com idade superior a 10 anos de idades usavam celular, o que em números absolutos significava 131 milhões de pessoas.

O Brasil encerrou o ano de 2013 com 217,1 milhões de linhas celulares ativas, o que dava uma densidade nacional no acesso à telefonia celular de 136,4\%. A título de comparação em 1998, ano das privatizações, havia no Brasil 7,4 milhões de celulares e 22,1 milhões de linhas de telefonia fixa instalada. (ANATEL, 2014). Fica claro que após as privatizações houve um salto quantitativo no acesso à telefonia.

Outro resultado importante a partir do fim do monopólio estatal foi o término da prática do autofinanciamento da instalação de linhas telefônicas pelo consumidor. Se nesse regime o preço pago por uma linha chegou a US\$ 2000 e havia um prazo de dois anos para a instalação de uma linha fixa. Hoje, por regulação, o tempo máximo de espera para a instalação de uma linha de telefonia fixa é de 7 dias úteis. No estado de Goiás para a instalação de uma linha telefônica fixa simples da OI, o cliente terá que pagar uma taxa de 120 reais de instalação que pode ser dividida em 12 meses. E pagar a franquia mensal de 19,90 mensais. Apesar disso o número de linhas telefônicas fixas instaladas apresenta estagnação nos últimos anos que segundo Anatel (2014), pode representar a substituição do uso da telefonia fixa pela telefonia celular.

Figura 1: Número de telefones fixos em serviço (em milhões)

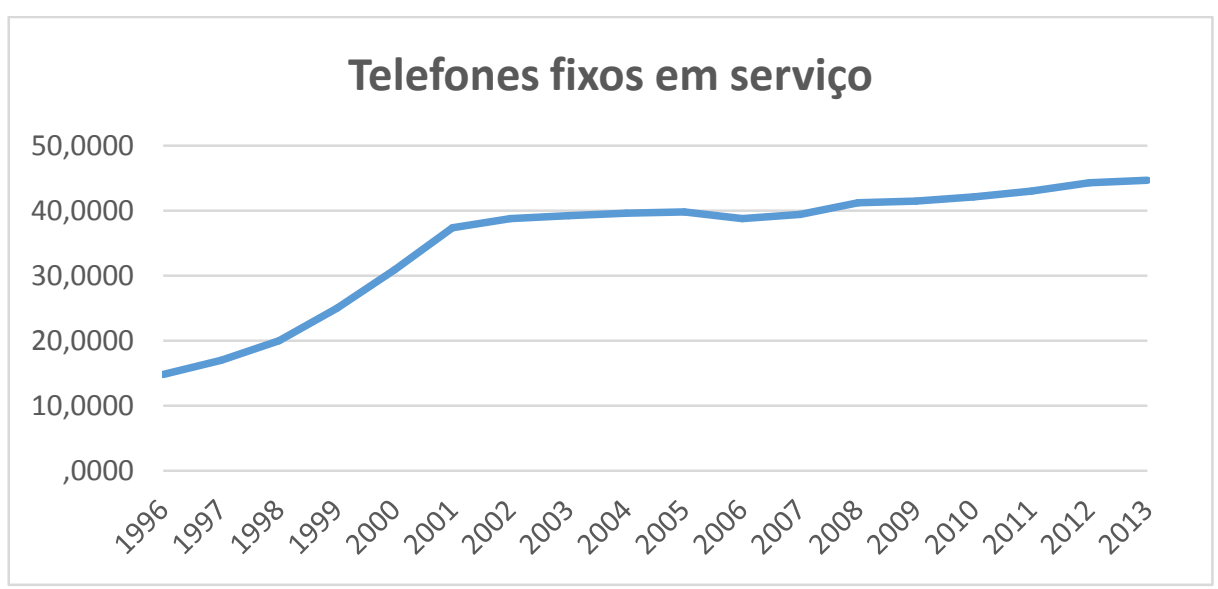

Elaborado pelo autor com base nos dados da Anatel 
Figura 2: Números de telefones móveis em serviço (em milhões)

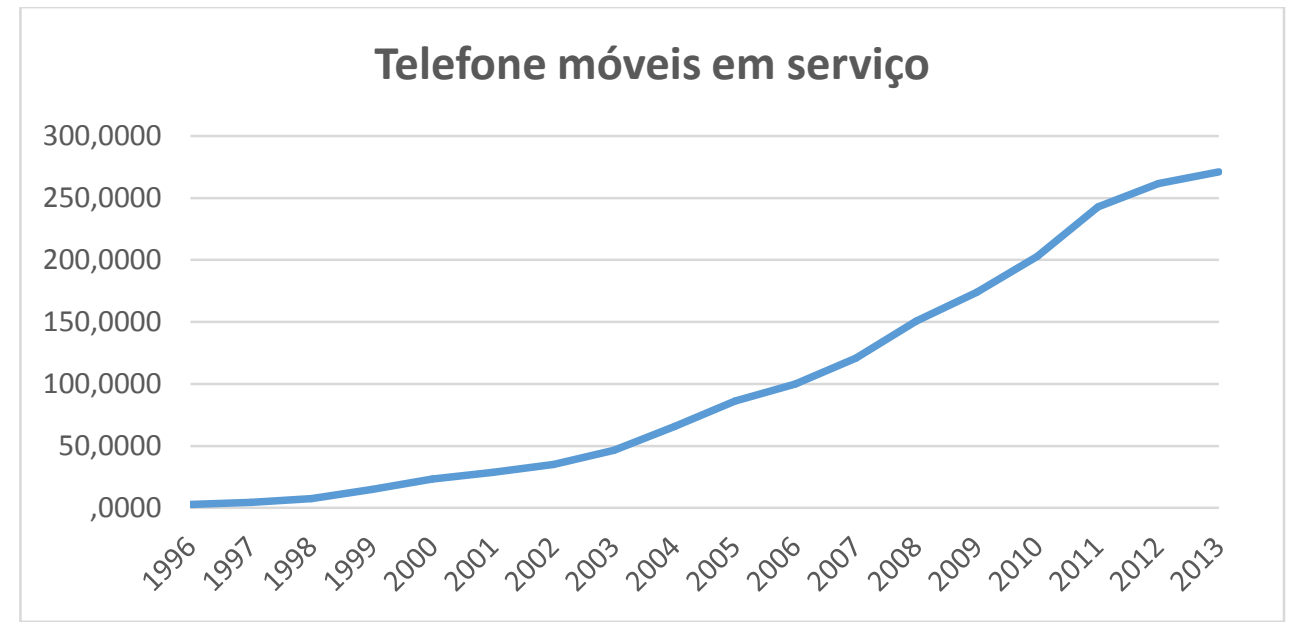

Elaborado pelo autor com base nos dados da Anatel

Na telefonia móvel uma das preocupações do governo durante as privatizações foi o esforço para a não criação de um monopólio privado. Para isso, houve a cisão de Telebrás e a implementação de empresas espelho. Apesar disso, houve várias fusões após as privatizações e hoje existem apenas quatro empresas que ofertam serviços de telefonia celular nacionalmente. Como resultado disso, o setor de telefonia celular apresenta um alto índice de concentração em todas as regiões nacionais e consequentemente no país como um todo. (RODRIGUES, CASARI, BASTOS, 2014).

Tabela 3: Market share das operadoras de telefonia celular

\begin{tabular}{c|c|c|c|c|c}
\hline Operadora & $\mathbf{2 0 1 0}$ & $\mathbf{2 0 1 1}$ & $\mathbf{2 0 1 2}$ & $\mathbf{2 0 1 3}$ & jul/14 \\
\hline Vivo & $29,71 \%$ & $29,54 \%$ & $29,08 \%$ & $28,49 \%$ & $28,75 \%$ \\
\hline TIM & $25,14 \%$ & $26,46 \%$ & $26,88 \%$ & $27,09 \%$ & $26,93 \%$ \\
\hline Claro & $25,44 \%$ & $24,93 \%$ & $24,92 \%$ & $25,34 \%$ & $24,96 \%$ \\
\hline Oi & $19,35 \%$ & $18,78 \%$ & $18,81 \%$ & $18,52 \%$ & $18,50 \%$ \\
\hline Algar & $0,30 \%$ & $0,27 \%$ & $0,28 \%$ & $0,37 \%$ & $0,40 \%$ \\
\hline Nextel & - & - & - & $0,12 \%$ & $0,39 \%$ \\
\hline Sercomtel & $0,04 \%$ & $0,03 \%$ & $0,03 \%$ & $0,02 \%$ & $0,02 \%$ \\
\hline Outras* & $0,01 \%$ & - & $0,03 \%$ & $0,04 \%$ & $0,04 \%$ \\
\hline Celulares & 202.944 & 242.232 & 261.808 & 271.100 & 276.153 \\
\hline
\end{tabular}

Fonte: Teleco (2014)

Essa concentração de mercado pode gerar baixa concorrência, o que explicaria a situação das tarifas praticadas no país. Em estudos realizados por órgãos internacionais o Brasil é apontado sempre entre os países com as tarifas mais caras. O da União Internacional de Telecomunicações (Measuring the Information Society, 2012) colocava o Brasil como o $93^{\circ}$ país de um total de 161 com a maior tarifa telefônica. 
Outro ponto onde a presença de concorrência poderia exercer resultado é sobre a qualidade do serviço ofertado. E esse é um ponto problemático, que teve como ápice a suspensão em julho de 2012 da venda de chips da Claro, Tim e Oi em vários estados, pelo período de onze dias, em consequência das reclamações dos usuários. (BORBA, 2012) Em 2013 no Ranking do PROCON - SP das empresas mais reclamadas, as quatro maiores empresas de telefonia estavam entre as dez mais reclamadas, sendo a Claro a $1^{\circ}$, Vivo a $3^{\circ}, \mathrm{OI}$ a $4^{\circ}$ e a TIM a $7^{\circ}$. Apesar disso segundo pesquisa realizada pela Anatel (Pesquisa Nacional de Satisfação dos Usuários dos Serviços de Telecomunicações), 85,9\% dos usuários da telefonia móvel pós paga achavam a prestação de serviços satisfatória. Esse número sobe para 91,7 quando considerado os usuários dos serviços pré-pagos. (ANATEL, 2014) Esses dados de satisfação à primeira vista são contraditórios com o Ranking do PROCON. A hipótese que se pode levantar é que sendo o ranking construído com base nos números absolutos de reclamações, o alto número de linhas de telefonia celular influenciaria no posicionamento das empresas de telecomunicações, entretanto, para ter um resultado confiável seria necessário um estudo específico sobre isso.

Um aspecto regulatório que continua em aberto é a questão sobre as instalações de Estações de Rádio Base (ERB). Hoje as empresas de telecomunicações têm de se submeter tanto a leis nacionais, quanto a regulações municipais. As empresas de telefonia alegam que tais dificuldades para a instalação das ERBs, são as principais responsáveis pelos problemas da telefonia. A solução prevista para esse problema seria a aprovação da Lei Geral de Antenas (PLS 293/2012) que tramita no Congresso Nacional desde 2012. Essa lei na sua redação original estipulava um prazo máximo 60 dias para deliberação sobre pedido de instalação de antenas, e o descumprimento desse prazo resultaria em autorização imediata para a instalação da antena, mas os deputados excluíram esse dispositivo, alegando que o mesmo fere princípio constitucional da autonomia dos entes federativos, fazendo o projeto de lei voltar para o Senado. Até o momento essa situação segue indefinida. (Altafin, 2014)

Na próxima seção são feitas as considerações finais.

\section{Considerações finais}

O objetivo primário de caracterizar o processo de desestatização do setor de telecomunicações foi feito na seção 5. Embora tenham aparecido denúncias posteriores, é possível notar que as privatizações das telecomunicações foram levadas a cabo com um grande cuidado de evitar alguns problemas, como a geração de um monopólio privado ou o 
risco institucional. O valor do ágio conseguido sobre os preços mínimos demonstram que as reformas feitas para preparar o setor para ser leiloado alcançaram sucesso.

Hoje o acesso à telefonia foi praticamente universalizado, ainda que não via telefonia fixa, mas sim via telefonia móvel. Apesar disso as empresas de telefonia móvel estão entra as mais reclamadas no PROCON. Há diversas causas para esses problemas, desde o grande número de linhas de celular habilitadas e a dificuldade da infraestrutura das empresas de telefonia celular em acompanhar tal avanço. Um dos problemas é a sobreposição de legislação, tanto municipal quanto federal no que se trata da implantação de novas torres de transmissão. Baseando-se na melhora relativa que se observou nas telecomunicações a partir do momento que houve um planejamento mais geral, com as mudanças da década de 60, uma boa ideia seria ter diretrizes nacionais já estabelecidas, que definissem as áreas passíveis de implantação de antenas de transmissão e um menor poder municipal para a criação de regulamentações.

A principal lição retirada do processo de privatizações do setor de telecomunicações e da sua situação posterior às privatizações é que o Estado quando se concentrou em delimitar as regras que prevaleceriam no setor e supervisionar o respeito à tais regras, teve melhores resultados do que quando buscou agir de maneira direta no mercado, buscando ofertar serviços que poderiam ser ofertados pela iniciativa privada. $\mathrm{O}$ desafio que fica para o futuro é a constante revisão e modernização das normas regulatórias, para que essas estejam sempre de acordo com as mudanças tecnológicas. A aprovação da Lei Geral de Antenas que criaria normas nacionais claras para a instalação da infraestrutura necessária para um melhor sinal telefônico e o cuidado da Anatel para a manutenção da frágil concorrência existente no setor de telefonia 


\section{REFERÊNCIAS}

AGÊNCIA NACIONAL DE TELECOMUNICAÇÕES. Relatório Anual 2013. ANATEL. [S.1.], p. 178. 2014.

ALTAFIN, I. G. Site do Senado Federal, 2014. Disponivel em: <http://www12.senado.gov.br/noticias/materias/2014/07/28/modificada-na-camara-lei-geraldas-antenas-volta-ao-senado/>. Acesso em: 10 novembro 2014.

ANUATTI NETO, F. et al. Costs and benefits of Privatization: Evidence from Brazil. Reseach Network Working Paper \#R-455, Junho 2003.

BANCO NACIONAL DO DESENVOLVIMENTO ECONÔMICO E SOCIAL. BNDES, $2002 . \quad$ Disponivel em: <http://www.bndes.gov.br/SiteBNDES/export/sites/default/bndes_pt/Galerias/Arquivos/conhe cimento/especial/Priv_Gov.PDF>. Acesso em: 3 novembro 2014.

BORBA, J. Mercado. Site da Folha de S. Paulo, 2012. Disponível em: $<$ http://www1.folha.uol.com.br/fsp/mercado/58367-teles-suspensas-voltam-hoje-a-venderchip.shtml>. Acesso em: 10 novembro 2014.

BRASIL. Decreto $n^{\circ} 2.592$, de 15 de maio de 1998. Aprova o Plano Geral de Metas para a Universalização do Serviço Telefônico Fixo Comutado Prestado no Regime Público. Disponível em: < http://www.planalto.gov.br/ccivil_03/decreto/d2592.htm>.

BRASIL. Lei $\mathrm{n}^{\mathrm{o}}$ 4.117, de 27 de agosto de 1962. Institui o Código Brasileiro de Telecomunicações. Disponível em: < http://www. planalto. gov. br/ccivil_03/Leis L, v. 4117>.

BRASIL. Lei ${ }^{\circ}$ 5.792, de 11 de julho de 1972. Institui política de exploração de serviços de telecomunicações, autoriza o Poder Executivo a constituir a empresa Telecomunicações Brasileiras S.A. - TELEBRÁS, e dá outras providências. Disponível em: <http://www2.camara.leg.br/legin/fed/lei/1970-1979/lei-5792-11-julho-1972-357850-normapl.html>.

BRASIL. Lei $\mathrm{n}^{\circ}$ 9.295, de 19 de julho 1996. Dispõe sobre os serviços de telecomunicações e sua organização, sobre o órgão regulador e dá outras providências. Disponível em: < http://www.planalto.gov.br/ccivil_03/leis/L9295.htm>.

BRASIL. Lei $n^{o}$ 9.472, de 16 de julho 1997. Dispõe sobre a organização dos serviços de telecomunicações, a criação e funcionamento de um órgão regulador e outros aspectos institucionais, nos termos da Emenda Constitucional $\mathrm{n}^{\circ}$ 8, de 1995. Disponível em: < http://www.planalto.gov.br/ccivil_03/leis/L9472.htm>.

CAVALCANTE, S. As telecomunicações após uma década da privatização: A face oculta do "sucesso". Revista electronica internacional de economia política da informação, da comunicação e da cultura, p. 166-183, 2011.

CENTRO REGIONAL DE ESTUDOS PARA O DESENVOLVIMENTO DA SOCIEDADE DA INFORMAÇÃO SOB AUSPÍCIOS DA UNESCO. Tic Domicílios. UNESCO. [S.1.]. 2013.

CHONG, A.; LOPEZ-DE-SILANES, F. The truth about privatization in Latin America. Banco Interamericano de Desenvolvimento. [S.1.]. 2003. 
GIAMBIAGI, F.; PINHEIRO, A. C.; MOREIRA, M. M. O Brasil na década de 90: uma transição bem-sucedida? Textos para Discussão, Rio de Janeiro, n. 91, novembro 2001.

INTERNATIONAL TELECOMMUNICATION UNION. Measuring the Information Society. ONU. Genebra, p. 214. 2012.

LINS, B. E. Privatização das telecomunicações brasileiras: algumas lições. Câmara dos Deputados. [S.1.]. 2000.

MEGGINSON, W. L.; NETTER, J. M. From State to Market: A Survey of Empirical Studies on Privatization. Jounal of Economic Literature, v. 39, Junho 2001.

NOVAES, A. A Privatização no Brasil: Privatização do Setor de Telecomunicações no Brasil. BNDES. [S.1.]. 2000.

PIMENTA, M. A. O comércio Eletrônico e a Privatização do Sistema Telebrás. Revista Informática Pública, 1999.

PINHEIRO, A. C. A experiência brasileira de privatização: o que vem a seguir. Textos para Discussão, Rio de Janeiro, n.87, 2000.

RODRIGUES, J. R. V.; CASARI, P.; BASTOS, A. D. C. Concentração do mercado de telefonia móvel: uma análise regional de 2006 a 2012. Latin Americna Journal of Business Management, América do Norte, 5 agosto 2014.

TATSCH, C. R. Privatização das telecomunicações. Universidade Federal do Rio Grande do Sul. Porto Alegre. 2003.

TELECO. Telefonia Celular. Teleco, 2014. Disponivel em: <http://www.teleco.com.br/mshare.asp>. Acesso em: 10 novembro 2014.

VELASCO JR, L. A Economia Brasileira nos Anos 90: Mitos e Falsas Percepções. BNDES. [S.1.]. 1999. 